\title{
The Relation Between Physical and Risk-Neutral Cumulants
}

\author{
Eric C. Chang \\ School of Economics and Finance \\ The University of Hong Kong \\ Pokfulam Road, Hong Kong \\ Email: ecchang@business.hku.hk \\ Jin E. Zhang \\ School of Economics and Finance \\ The University of Hong Kong \\ Pokfulam Road, Hong Kong \\ Email: jinzhang@hku.hk \\ Huimin Zhao ${ }^{1}$ \\ School of Economics and Finance \\ The University of Hong Kong \\ Pokfulam Road, Hong Kong \\ Email: hmzhao@hku.hk
}

First Version: January 2009

\begin{abstract}
Variance swaps are natural instruments for investors taking directional bets on volatility and are often used for portfolio protection. But the crucial observation suggests that derivative professionals may desire to hedge beyond volatility risk and there exists the need to hedge higher-moment market risks, such as skewness and kurtosis risks. We propose new derivative contracts: skewness swap and kurtosis swap, which trade the forward realized third and fourth cumulants. Using S\&P 500 index options data from 1996 to 2005, we document the returns of these swap contracts, i.e., skewness risk premium and kurtosis risk premium. We find that the skewness risk premium is significantly negative and kurtosis risk premium for 90 day maturity is significantly positive.
\end{abstract}

Keywords: Skewness swap; Kurtosis swap; Equity risk premium; Variance risk premium; Skewness risk premium; Kurtosis risk premium

\footnotetext{
${ }^{1}$ Corresponding author. Tel: (852) 2241 5685, Fax: (852) 2548 1152. Jin E. Zhang has been supported by a grant from the Research Grants Council of the Hong Kong Special Administrative Region, China (Project No. HKU 7427/06H).
} 
JEL Classification Code: G12; G13 


\title{
The Relation Between Physical and Risk-neutral Cumulants
}

\begin{abstract}
Variance swaps are natural instruments for investors taking directional bets on volatility and are often used for portfolio protection. But the crucial observation suggests that derivative professionals may desire to hedge beyond volatility risk and there exists the need to hedge higher-moment market risks, such as skewness and kurtosis risks. We propose new derivative contracts: skewness swap and kurtosis swap, which trade the forward realized third and fourth cumulants. Using S\&P 500 index options data from 1996 to 2005, we document the returns of these swap contracts, i.e., skewness risk premium and kurtosis risk premium. We find that the skewness risk premium is significantly negative and kurtosis risk premium for 90 day maturity is significantly positive.
\end{abstract}




\section{Introduction}

It is well known that managing volatility is central to hedging the risk in an options portfolio. Variance swaps offer investors a straightforward vehicle for achieving long or short exposure to market volatility. Investors trade volatility (variance) by swap contracts. In late 1990s, Wall Street firms started to trade variance swaps, a forward contract with a payoff based on the realized variance of a stated equity index. In late 1998, variance swaps became very popular. According to some estimates, the daily trading volume in equity index variance swaps reached USD 4-5 million vega notional in 2006. On an annual basis, this corresponding to payments of more than USD 1 billion, per percentage point of volatility (Carr and Lee (2009)).

Variance swaps are natural instruments for investors taking directional bets on volatility and are often used for portfolio protection. Variance swaps are especially attractive to volatility traders for two reasons:(1) implied volatility of an exchange traded option tends to be higher than the realized volatility; (2)the payoff of a variance swap is convex in volatility (volatility skew)(Bossu, Strasser and Guichard (2005)). Evidence supporting the first reason has been well documented in that the Black-Scholes implied volatilities of at-the-money options are systematically and consistently higher than realized volatilities of the underlying. Negative volatility risk premium, the difference between the physical and risk-neutral volatilities, is regarded as a major explanation for this seemingly puzzling evidence by researchers (Bakshi and Kapadia (2003)). The second reason has also been studied. Rubinstein (1994) empirically documents that the implied volatility as a function of the strike price has been skewed towards the left since the market crash in 1987. In particular, the downward slope of the smirk reflects asymmetry (negative skewness) in the risk-neutral distribution of the underlying index return (Carr and Wu (2003)). Together, they contribute to the huge sucess of the variance swaps market. Robinstein (1994) and 
Dennis and Mayhew (2002) also show that risk-neutral skewness tends to be more negative in periods of high market volatility and when the market skew is negative.

This crucial observation suggests that derivative professionals may desire to hedge beyond volatility risk and there exists the need to hedge higher-moment market risks, such as skewness and kurtosis risks. In fact, deviations of physical densities from riskneutral(implied) densities have led to skewness and kurtosis trading strategies. Ait-Sahalia, Wang and Yared (2001) and Balskowitz and Schmidt (2002) investigate such strategies for the period from April 1997 until December 1999 and document that the trades applied to European options on the German DAX index generated a positive net cash flow. Blaskowitz, Hardle and Schmidt (2003) investigate the profitability of skewness trades and kurtosis trades by derivatives market option strategies based on comparisons of implied state price densities versus historical densities. Traditionally, volatility trading requires both buying and selling options, but from time to time traders find that their brokerage firms do not facilitate options sellings as straightforward as options buying. By variance swaps, traders can now have easy access to volatility trades. Accordingly, we propose two new derivative contracts: skewness swap and kurtosis swap that will trade skewness and kurtosis risks directly. We offer in this paper some fundamental understanding of the risk premium properties of these two potential contracts.

Following the definition of variance swap, skewness and kurtosis swaps are proposed to trade the forward third and fourth central moments. Carr and Wu (2009) develop a method to measure the return variance risk premium by a variance swap contract that pays the difference between a standard estimate of the realized variance and the fixed variance swap rate which equals the risk-neutral future realized variance. Given the reasons that have contributed to the success of variance swaps, it is of great interest to know whether or not the skewness/kurtosis risk premia defined by the difference between the physical and risk-neutral third/fourth central moments are non-zero. 
The variance swap is a contract in which two parties agree to exchange cash flows based on the measured variance of a specified underlying asset during a certain time period. On the trade date, the two parties agree on the strike price of the contract (the reference level against which cash flows are exchanged), as well as the number of units in the transaction. Following Carr and $\mathrm{Wu}(2009)$ that the fair strike price of the variance swap is the riskneutral second central moment of the underlying asset return, we propose that the fair strike price of the skewness/kurtosis is defined by the risk-neutral third/fourth central moments. Thus, the skewness/kurtosis swap contract is designed as the same manner in spirit as the variance swap contract except the strike price of the contract.

We define the premia of skewness and kurtosis risks estimated as the difference between the physical and risk-neutral central moments. Using S\&P 500 index options data from 1996 to 2005, we study the properties of the risk premia.

To estimate the risk-neutral standard deviation, skewness and kurtosis efficiently, we adopt the methodology developed by Zhang and Xiang (2008) based on the implied volatility smirk. We infer the risk-neutral higher order cumulants from options with 30, 60 and 90 days to maturity. By comparing these risk-neutral cumulants with the subsequent realized physical cumulants, we can study the risk premium of higher order cumulants. We find that S\&P 500 index return has a significant negative variance risk premium and a significant negative skewness risk premium. Kurtosis risk premium is significant for a long maturity.

This paper makes two contributions. First, this paper is the first to offer a justification and to propose the trading of the skewness swap and kurtosis swap contracts, which trade the forward realized third and fourth cumulants. Second, this is the first paper to document the signs and magnitudes of skewness and kurtosis premium.

The rest of this paper is organized as follows. Section 2 gives the definitions and calculations of physical and risk-neutral cumulants. Section 3 describes the trading of the second order cumulants. Trading the third and fourth cumulants are given in Section 4 . 
Section 5 describes the data for our empirical study. Section 6 presents our empirical study results. Section 7 concludes.

\section{Definitions and calculations of Physical and Risk- neutral Cumulants}

\subsection{Cumulants of a random variable}

In probability theory and statistics, the first cumulant of a random variable $X$ is defined as its expected value $\kappa_{1}=\mu=E(X)$. Its second cumulant is defined as the variance $\kappa_{2}=\sigma^{2}=E\left((X-\mu)^{2}\right)$.

The higher order cumulants $\kappa_{n}$ are defined by the cumulant-generating function:

$$
g(t)=\ln \left(E\left(e^{t \cdot X}\right)\right)=\sum_{n=1}^{\infty} \kappa_{n} \frac{t^{n}}{n !}=\mu t+\sigma^{2} \frac{t^{2}}{2}+\cdots
$$

where $t$ is the parameter. Then we have :

$$
\begin{aligned}
& \kappa_{1}=E(X)=g^{\prime}(0), \\
& \kappa_{2}=\operatorname{Var}(X)=g^{\prime \prime}(0), \\
& \kappa_{n}=g^{(n)}(0) .
\end{aligned}
$$

Working with cumulants has an advantage over using moments, because for independent variables $X$ and $Y$,

$$
\begin{aligned}
g_{X+Y}(t) & =\ln \left(E\left(e^{t \cdot(X+Y)}\right)\right)=\ln \left(E\left(e^{t X}\right) \cdot E\left(e^{t Y}\right)\right) \\
& =\ln \left(E\left(e^{t X}\right)\right)+\ln \left(E\left(e^{t Y}\right)\right)=g_{X}(t)+g_{Y}(t),
\end{aligned}
$$

therefore the cumulants of the sum of two independent random variables are the sum of the corresponding cumulants of the addends. 
Some prefer to define the cumulant generating function $g(t)$ via the characteristic function $h(t)$, which is

$$
h(t)=\ln \left(E\left(e^{i t X}\right)\right)=\sum_{n=1}^{\infty} \kappa_{n} \cdot \frac{(i t)^{n}}{n !}=\mu i t-\sigma^{2} \frac{t^{2}}{2}+\cdots
$$

The two functions are related by $h(t)=g(i t)$ and where $i$ is the standard imaginary unit.

This characterization of cumulants is valid even for distributions whose higher moments do not exist.

\subsection{The relation between cumulants and moments}

The cumulants of a random variable are closely related to its moments. The moment generating function, $M_{n}$, is defined:

$$
1+\sum_{n=1}^{\infty} \frac{M_{n} t^{n}}{n !}=\exp \left(\sum_{n=1}^{\infty} \frac{\kappa_{n} t^{n}}{n !}\right)=\exp (g(t)),
$$

therefore, the cumulant generating function is the logarithm of the moment generating function. The third cumulant is the third central moment, and the fourth cumulant is the fourth central moment minus three times the square of the variance. The higher cumulants are neither moments nor central moments, but rather more complicated polynomial functions of the moments.

We summarize the relation between the first four moments and cumulants are given as 
follows:

$$
\begin{aligned}
M_{1} & =\kappa_{1}, \\
M_{2} & =\kappa_{2}+\kappa_{1}^{2}, \\
M_{3} & =\kappa_{3}+3 \kappa_{2} \kappa_{1}+\kappa_{1}^{3}, \\
M_{4} & =\kappa_{4}+4 \kappa_{3} \kappa_{1}+3 \kappa_{2}^{2}+6 \kappa_{2} \kappa_{1}^{2}+\kappa_{1}^{4}, \\
\kappa_{1} & =E(X)=M_{1}, \\
\kappa_{2} & =E\left[\left(X-M_{1}\right)^{2}\right]=M_{2}-M_{1}^{2}, \\
\kappa_{3} & =E\left[\left(X-M_{1}\right)^{3}\right]=M_{3}-3 M_{1} M_{2}+2 M_{1}^{3}, \\
\kappa_{4} & =E\left[\left(X-M_{1}\right)^{4}\right]-3 E\left[\left(X-M_{1}\right)^{2}\right]^{2} \\
& =M_{4}-4 M_{1} M_{3}-3 M_{2}^{2}+6 M_{1}^{2} M_{2}+6 M_{1} M_{2}-6 M_{1}^{4} .
\end{aligned}
$$

\subsection{Calculations of physical and risk-neutral cumulants of index returns}

\subsubsection{Physical cumulants}

The continuously compounded return of underlying asset with price $S_{t}$ during the period time $t$ to $T$ is defined as

$$
Y_{\tau}=\ln \left(S_{t+\tau} / S_{t}\right)
$$

where $\tau=T-t$.

Following Carr and $\mathrm{Wu}$ (2009), we use the realized cumulants as the proxies of physical cumulants. Based on the daily data and set $\tau=1 / 252$, the first physical cumulant can be calculated from the daily stock price, $S_{i}$, as follows:

$$
\kappa_{1}=\frac{1}{n-1} \sum_{i=1}^{n-1} \ln \left(S_{i+1} / S_{i}\right),
$$

where $n$ is the total number of the daily observations over the estimation interval. $S_{i}$ is the $i$-th observation and $S_{i+1}$ is the price value of the following trading day (all the values of 
cumulants calculated are annualized).

The second, third and fourth physical cumulants at time $t$ for $n$ daily observations are calculated from the following equations:

$$
\begin{aligned}
\kappa_{2} & =\frac{1}{n-1} \sum_{i=1}^{n-1}\left[\ln \left(S_{i+1} / S_{i}\right)-\kappa_{1}\right]^{2}, \\
\kappa_{3} & =\frac{n}{(n-1)(n-2)} \sum_{i=1}^{n-1}\left[\ln \left(S_{i+1} / S_{i}\right)-\kappa_{1}\right]^{3}, \\
\kappa_{4} & =\frac{n(n+1)}{(n-1)(n-2)(n-3)} \sum_{i=1}^{n-1}\left[\ln \left(S_{i+1} / S_{i}\right)-\kappa_{1}\right]^{4}-3 \kappa_{2},
\end{aligned}
$$

where the three coefficients before summations related to $n$ are due to the unbiased estimation rule in statistics.

\subsubsection{Risk-neutral cumulants}

We estimate the risk-neutral cumulants based on Zhang and Xiang's (2008) methodology. The implied volatility, IV, can be approximated by a second-order polynomial function of moneyness, i.e,

$$
I V(\xi)=\eta_{0}\left(1+\eta_{1} \xi+\eta_{2} \xi^{2}\right)
$$

where $\eta_{0}, \eta_{1}, \eta_{2}$ are the level, slope and curvature of the implied volatility smirk and $\xi$ is a measure of the moneyness which is defined by

$$
\xi \equiv \frac{\ln \left(K / F_{0}\right)}{\bar{\sigma} \sqrt{\tau}},
$$

where $\bar{\sigma}$ denotes a measure of the average volatility of the underlying asset return, $\tau$ is the option's maturity, $K$ is the strike price and $F_{0}$ is the forward price which is described in detail in the following sections.

Then we invoke the following proposition according to Zhang and Xiang (2008).

Proposition 1 The level, slope and curvature of the implied volatility smirk, $\left(\eta_{0}, \eta_{1}, \eta_{2}\right)$, and the risk-neutral standard deviation, skewness and excess kurtosis, $\left(\sigma^{Q}, \lambda_{1}^{Q}, \lambda_{2}^{Q}\right)$ are 
related by following leading-order result:

$$
\eta_{0} \approx\left(1-\frac{\lambda_{2}^{Q}}{24}\right) \sigma^{Q}, \quad \eta_{1} \approx \frac{1}{6} \lambda_{1}^{Q}, \quad \eta_{2} \approx \frac{1}{24}\left(1-\frac{\lambda_{2}^{Q}}{16}\right)
$$

If we further assume that $\frac{\lambda_{2}}{16} \ll 1$, then we obtain following simple result

$$
\eta_{0} \approx \sigma^{Q}, \quad \eta_{1} \approx \frac{1}{6} \lambda_{1}^{Q}, \quad \eta_{2} \approx \frac{1}{24} \lambda_{2}^{Q}
$$

After we obtain the risk-neutral standard deviation $\sigma^{Q}$, skewness $\lambda_{1}^{Q}$ and kurtosis $\lambda_{2}^{Q}$, by Proposition (1) and using the following relation, it is straightforward to obtain

$$
\kappa_{2}^{Q}=\sigma^{Q}, \quad \kappa_{3}^{Q}=\lambda_{1}^{Q}\left(\kappa_{2}^{Q}\right)^{3 / 2}, \quad \kappa_{4}^{Q}=\lambda_{2}^{Q}\left(\kappa_{2}^{Q}\right)^{2}
$$

\section{$3 \quad$ Variance Swaps}

\subsection{Variance swap rates}

A variance swap is an instrument which allows investors to trade future realized (or historical) volatility against current implied volatility. In late 1998, variance swaps became very popular in the aftermath of LTCM meltdown when implied stock index volatilities rose to unprecedented levels. Hedge funds took advantage of this by selling the realized volatility at high implied levels. A return variance swap has zero net market value at entry. At maturity, the payoff of a long side of the swap is equal to the difference between the realized variance and a constant called variance swap rate,

$$
\left[R V_{t, T}-S W_{t, T}\right] L
$$

where $R V_{t, T}$ denotes the realized annualized return variance between time $t$ and $T, S W_{t, T}$ denotes the fixed swap rate that is determined at time $t$ and paid at time $T$, and $L$ denotes the nominal dollar amount that converts the variance difference into a dollar payoff. No 
arbitrage dictates that the variance swap rate $S W_{t, T}$ equals the risk-neutral expected value of the realized variance, $R V_{t, T}$. That is,

$$
S W_{t, T}=E^{Q}\left[R V_{t, T}\right]
$$

Assume the underlying stock follows the process,

$$
\frac{d S_{t}}{S_{t}}=\mu d t+\sigma_{t} d B_{t}
$$

where the volatility $\sigma_{t}$ is a stochastic variable and $B_{t}$ is the standard Brownian motion. Then

$$
d\left(\ln S_{t}\right)=\left(\mu-\frac{1}{2} \sigma_{t}^{2}\right) d t+\sigma_{t} d B_{t}
$$

Subtracting these two equations gives

$$
\frac{d S_{t}}{S_{t}}-d\left(\ln S_{t}\right)=\frac{1}{2} \sigma_{t}^{2} d t
$$

The realized variance can be written as

$$
R V_{t, T}=\frac{1}{T-t} \int_{t}^{T} \sigma_{s}^{2} d s=\frac{2}{T-t}\left(\int_{t}^{T} \frac{d S_{u}}{S_{u}}-\ln \frac{S_{T}}{S_{t}}\right)
$$

The variance swap rate is then determined by

$$
S W_{t, T}=E^{Q}\left[R V_{t, T}\right]=\frac{2}{T-t} e^{r \tau}\left[\int_{0}^{F_{t}^{T}} \frac{1}{K^{2}} p_{t}(K) d K+\int_{F_{t}^{T}}^{\infty} \frac{1}{K^{2}} c_{t}(K) d K\right]
$$

Variance swap rate can be determined by the current price of all the out-of-money(OTM) European calls and puts. This formula was obtained by Carr and Madan (1998) and Demeterfi et al (1999) independently.

Recently, the Chicago Board Options Exchange (CBOE) designed a new volatility index, $\mathrm{VIX}^{2}$, by using discretized version of the formula.

\footnotetext{
${ }^{2}$ The definition of the VIX and the methodology of computing it from options prices are clearly described in the CBOE white paper (2003).
} 


\subsection{The relation between the variance swap rate and the risk- neutral variance}

The risk-neutral log return $\ln \left(S_{T} / S_{t}\right)$ can be written as the following:

$$
R=\ln \frac{S_{T}}{S_{t}}=\int_{t}^{T}\left(r-\frac{1}{2} \sigma_{s}^{2}\right) d s+\int_{t}^{T} \sigma_{s} d B_{s},
$$

then the risk-neutral variance is

$$
\begin{aligned}
E_{t}^{Q}\left[R-E_{t}^{Q}(R)\right]^{2}= & E_{t}^{Q}\left[\frac{1}{2}\left(\int_{t}^{T} \sigma_{s}^{2} d s-E_{t}^{Q} \int_{t}^{T} \sigma_{s}^{2} d s\right)-\int_{t}^{T} \sigma_{s} d B_{s}\right]^{2} \\
= & \frac{1}{4} E_{t}^{Q}\left[\int_{t}^{T} \sigma_{s}^{2} d s-E_{t}^{Q} \int_{t}^{T} \sigma_{s}^{2} d s\right]^{2}+E_{t}^{Q} \int_{t}^{T} \sigma_{s}^{2} d s \\
& -E_{t}^{Q}\left[\int_{t}^{T} \sigma_{s}^{2} d B_{s}\left(\int_{t}^{T} \sigma_{s}^{2} d s-E_{t}^{Q} \int_{t}^{T} \sigma_{s}^{2} d s\right)\right] \\
= & \frac{1}{4} \operatorname{var}\left(\int_{t}^{T} \sigma_{s}^{2} d s\right)+S W_{t, T} \\
& -E_{t}^{Q}\left[\int_{t}^{T} \sigma_{s}^{2} d B_{s}\left(\int_{t}^{T} \sigma_{s}^{2} d s-E_{t}^{Q} \int_{t}^{T} \sigma_{s}^{2} d s\right)\right]
\end{aligned}
$$

If the variance of $\sigma_{t}$ is small, the values of the first and third terms are relatively small compared with the variance swap rate $S W_{t, T}$, then

$$
S W_{t, T}=E_{t}^{Q}\left[R-E_{t}^{Q}(R)\right]^{2}+\epsilon_{t}
$$

where the error term $\epsilon_{t}$ depends on the detailed specification of $\sigma_{t}$ process.

Therefore, for simplification professionals usually use the risk-neutral variance as an approximation to the swap rate of the variance swap to understand the variance risk premium.

\section{Skewness and kurtosis swaps}

Motivated by the design of variance swap contracts traded actively on the Wall Street, we define two new derivative contracts: skewness swap and kurtosis swap. The skewness/kurtosis swap is a forward contract on realized third/fourth central moments. A 
return skewness/kurtosis swap also has zero net market value at entry as a return variance swap. At maturity, the payoff of a long side of the skewness/kurtosis swap is equal to the difference between the realized third/fourth central moments and a constant called skewness/kurtosis swap rate,

$$
\left[R 3 C_{t, T}-S W_{t, T}^{\text {third }}\right] L \quad / \quad\left[R 4 C_{t, T}-S W_{t, T}^{\text {fourth }}\right] L
$$

where $R 3 C_{t, T} / R 4 C_{t, T}$ denotes the realized annualized return third/fourth central moments between time $t$ and $T, S W_{t, T}^{\text {third }} / S W_{t, T}^{\text {fourth }}$ denotes the fixed swap rate that is determined at time $t$ and paid at time $T$, and $L$ denotes the nominal dollar amount that converts the third/fourth central moments difference into a dollar payoff. No arbitrage dictates that the skewness/kurtosis swap rate $S W_{t, T}^{\text {third }} / S W_{t, T}^{\text {fourth }}$ equals the risk-neutral expected value of the realized variance, $R V_{t, T}$. That is,

$$
\begin{aligned}
S W_{t, T}^{\text {third }} & =E_{t}^{Q}\left[R 3 C_{t, T}\right], \\
S W_{t, T}^{\text {fourth }} & =E_{t}^{Q}\left[R 4 C_{t, T}\right],
\end{aligned}
$$

where $R 3 C_{t, T} / R 4 C_{t, T}$ is the realized third/fourth central moments.

Carr and Wu (2007) document that jump diffusions induce short term smiles and skews that dissipate quickly with increasing maturity due to the central limit theorem, while stochastic volatility induces smiles and skews that increase as maturity increases over the horizon of interest. In order to understand the mechanism of skewness and kurtosis swap rates we need a much more complicated model, such as one with stochastic volatility or stochastic jump intensity. A theory of replicating the realized third/fourth cumulants by using options portfolio is yet to be developed.

Like the relation between variance swap rate and risk-neutral variance discussed in the previous section, the skewness/kurtosis swap rate is not equal, but very close to the riskneutral third/fourth central moments of log return over the period $[t, T]$. The detailed 
analysis, which depends on the processes of volatility and jump intensity, for example, see Carr and Wu (2004), is not elaborated here.

In this paper, we focus on the empirical study on the relation between physical and risk-neutral cumulants by using S\&P 500 index option data.

\section{Data}

We use the daily S\&P 500 closing index from January 4, 1996 to December 30, 2005 as our proxy for the underlying price. The total number of observations is 2514 . The risk-free rate used in our empirical study is from the U.S. daily treasury yield curve rates. We also retrieve the daily S\&P 500 index European options (including all the call and put options for different strike prices and maturities traded) data from OptionMetrics which provides historical prices of options based on closing quotes at the Chicago Board of Options Exchange. The range of our data sample is also from January 4, 1996 to December 30, 2005.

\section{Empirical results}

\subsection{Implied volatility smirk}

From Proposition 1, we know the relation between the risk-neutral standard deviation, skewness and excess kurtosis and the level, slope and curvature of the implied volatility smirk. We demonstrate in this subsection the procedures to obtain the implied volatility function by the S\&P 500 index European options data on September 6, 2002, as an example, for 30 days time to maturity.

We first select all the call and put options in the two nearest-term expiration months in order to bracket a 30-day calendar period. Specially, the near term 15 days and the next term 43 days options are chosen. 
For 15-day options, we observe that the options with at-the-money strike $K_{0}=900$, have the smallest difference between the call and put prices is the smallest. 15-day risk-free rate is extrapolated from the 1 month rate and the 3 month rate of U.S. treasury yield curve rates on September 6, 2002, i.e.,

$$
r=r_{1 m o n}-\left(r_{3 m o n}-r_{1 m o n}\right) \times \frac{30-15}{61}=1.66 \%-(1.66-1.68) \times 15 / 61=1.685 \% .
$$

As documented by Foresi and $\mathrm{Wu}$ (2005), the implied volatility of the US equity index options, as a function of strike/moneyness for a certain maturity, exhibits a negatively skewed curve for most of the index options. Following Zhang and Xiang (2008), the implied volatility, IV, can be approximated by a second-order polynomial function of moneyness, like equations (15) and (16). In our data analysis, we use at the money implied volatility as a proxy of $\bar{\sigma} . F_{0}$ is the implied forward price and is determined based on at-the-money option prices:

$$
\begin{aligned}
F_{0} & =K_{0}+e^{r \tau} *(\text { Call price }- \text { Put price })_{A T M} \\
& =900+e^{1.685 \% \times 15 / 365}(18.9-24.85)=894.289,
\end{aligned}
$$

where call prices and put calls are the midpoints of the bid-ask spread for each European option with strike K.

Since put-call parity holds, the market data of either call or put give the same value of the implied volatility. We use out-of-money options to compute the implied volatilities for different strikes. When the strike is $K<900$ or $K>900$, implied volatilities are calculated from the put and call options respectively by the Black-Scholes formula. At-the-money implied volatility, denoted by $\bar{\sigma}$, can be calculated by its call or put. We obtain two time series for implied volatilities and corresponding moneyness values $\xi$ with different strike prices $K$ for 15 day maturity on September 6, 2002. ["For a given day, there are different strike $\mathrm{K}$ and for every $\mathrm{k}$, we have a corresponding implied volatility and moneyness"] 
We follow the calculating method of Chicago Board Options Exchange (CBOE) Volatility Index, VIX, to construct the options with 30-day maturity. We use a quadratic function to fit the implied volatilities by minimizing the volume weighted mean squared error

$$
\frac{\sum_{\xi} V o l_{i} \times\left[I V_{i}-\bar{\sigma}\left(1+\eta_{1} \xi+\eta_{2} \xi^{2}\right)\right]}{\sum_{\xi} V o l_{i}},
$$

where $\bar{\sigma}, \eta_{1}$ and $\eta_{2}$ are defined in Equations (15) and (16). Accordingly, we obtain

$$
I V(\xi)=0.3237\left(1-0.1614 \xi+0.0106 \xi^{2}\right)
$$

or the smirk parameters of the day on September 6, 2002 for 15 days maturity, $\left(\eta_{0}^{1}, \eta_{1}^{1}, \eta_{2}^{1}\right)=$ $(0.3237,-0.1614,0.0106)$.

Repeating the above procedures, we have the smirk parameters for 43 time to maturity on September 6, 2002, $\left(\eta_{0}^{2}, \eta_{1}^{2}, \eta_{2}^{2}\right)=(0.3219,-0.2274,0.0095)$.

The implied volatility smirk for 15 days and 43 days time to maturity on September 6, 2002 is shown graphically in Figure 2. It is obvious that they fit quite well except for points corresponding to approximate zero trading volumes.

We then use the extrapolation technique as it is used by CBOE for VIX ${ }^{3}$ to compute the smirk parameters for 30 days time to maturity. The level $\eta_{0}$, the slope $\eta_{1}$ and the curvature $\eta_{3}$ of the implied volatility smirk for 30 days time to maturity is shown as follows:

$$
\begin{aligned}
& \eta_{0}=\frac{14}{30} \times \frac{42-30}{42-14} \eta_{0}^{1}+\frac{42}{30} \times \frac{30-14}{42-14} \eta_{0}^{2}=0.3222, \\
& \eta_{1}=\frac{14}{30} \times \frac{42-30}{42-14} \eta_{1}^{1}+\frac{42}{30} \times \frac{30-14}{42-14} \eta_{1}^{2}=-0.2142, \\
& \eta_{2}=\frac{14}{30} \times \frac{42-30}{42-14} \eta_{2}^{1}+\frac{42}{30} \times \frac{30-14}{42-14} \eta_{2}^{2}=0.0097 .
\end{aligned}
$$

Using the same method, we can obtain these parameters of implied volatility smirk for 60 days and 90 days time to maturities.

\footnotetext{
${ }^{3}$ see white paper, "VIX-CBOE volatility index", CBOE (2003)
} 


\subsection{Equity risk premium}

We define the equity risk premium is defined as the excess average return earned by an individual stock or the overall stock market index over the corresponding risk-free rate. It compensates investors for taking on the relatively higher risk in the equity market. The size of the premium will vary with time as well as the risk.

Suppose that the expected compound return of an asset is expressed as

$$
\mu=E_{t}\left[\ln \left(S_{t+d t} / S_{t}\right)\right]
$$

Then the equity premium $\phi$ is

$$
\phi=\mu-r \text {. }
$$

If $d t$ is $1 / 252$, then $\mu$ is the daily mean return.

Table 1 reports the summary of the equity premium (annualized) from January 3, 1996 to December 31, 2005. The past realized excess return roughly can be divided into three stages. The first stage is from 1996 to 2000 in which investors earned a positive high excess return. 2000 to 2002 defines the second stage, where the average excess returns are large negative numbers, even as low as $-24.86 \%$ in year 2002. In the final stage the average annual excess returns increase and become positive again, but are still not as high as the average levels of the first stage. We note that investors bore a lower volatility over this period than that in the first stage.

The partition for the three stages is roughly matching to the episodes of the "dotcom bubble" (or sometimes the "I.T. bubble"). By 2001 the bubble burst drastically and investors incurred a great loss with high volatility in the second stage. Table 2 shows clearly that volatility or variance of return is not constant. It could be another source of risk that needs to be compensated. Buyers of market volatility are arguably willing to pay a premium for downside protection and the hedging motives is indicative of a negative 
volatility (variance) risk premium (Bakshi and Kapadia (2003)). Empirical studies show that increased realized volatility coincides with downward market moves (French, Schwert and Stambaugh (1987)). This could induce negative variance risk premium.

In equilibrium, risk averse investors are expected to be properly compensated for any risk that is taken. Conceptually, this is not confined to volatility risk. The intuition motives the need to further explore higher order risks, such as skewness risk and kurtosis risk.

\subsection{Variance risk premium}

According to the condition and Equations (17) and (18) in Proposition 1, it is straightforward to get the risk-neutral variance, skewness and excess kurtosis, $\left(\sigma_{r n}^{2}, \lambda_{1}^{Q}, \lambda_{2}^{Q}\right)$, for 30 days time to maturity contract on September 6, 2002 (as an example),

$$
\begin{aligned}
\sigma_{r n}^{2} & =\eta_{0}^{2}=0.32222^{2}=0.1038, \\
\lambda_{1}^{Q} & =6 \eta_{1}=6 \times(-0.2162)=-1.2972, \\
\lambda_{2}^{Q} & =24 \eta_{2}=24 \times 0.0097=0.2328 .
\end{aligned}
$$

From Equation (19), we have the 2nd, 3rd and 4th central moments $\left(M^{c}\right)$ in risk-neutral measure for 30 days time to maturity

$$
\begin{aligned}
& M_{2}^{c}=\kappa_{2}^{Q}=\sigma_{r n}^{2}=0.1038 \\
& M_{3}^{c}=\kappa_{3}^{Q}=\lambda_{1}^{Q}\left(\kappa_{2}^{Q}\right)^{3 / 2}=-1.2972 \times(0.1038)^{3 / 2}=-0.0434, \\
& M_{4}^{c}=\kappa_{4}^{Q}+3\left(\kappa_{2}^{Q}\right)^{2}=\left(\lambda_{2}^{Q}+3\right)\left(\kappa_{2}^{Q}\right)^{2}=(0.2328+3) \times(0.1038)^{2}=0.03483 .
\end{aligned}
$$

Using the same method, risk-neutral 2nd, 3rd and 4th central moments for 60 days and 90 days can be obtained.

Since variance risk premium is defined as the difference between physical (realized) and risk-neutral variance, we also need to compute the physical variance with the same time horizon. 
Figures 3, 4 and 5 plot the time series of physical variance, risk-neutral variance and variance risk premium for 30 days, 60 days and 90 days time to maturities respectively from January 4, 1996 to December 31, 2005. Table 2 reports the summary statistics for the whole sample and sub-periods. To test whether the variance risk premium is negative or not, we state the null-hypothesis as: $H_{0}: \mu_{v a r} \geq 0$. For example, t-statistics for this one-tailed test for 30 days time to maturity over the whole sample period is

$$
t=\frac{\overline{\text { difvar }}-0}{\sigma_{\text {var }} / \sqrt{n}}=\frac{-0.00577}{0.02516 / \sqrt{2516}}=-11.95,
$$

where $\overline{\text { difvar }}$ is the average of the time series of difference between physical and riskneutral variance, $\sigma_{v a r}$ is the standard deviation of this sample and $n$ is the number of the observations of the sample.

The results shows that the average variance risk premium for 30 days time to maturity is significantly negative at the $1 \%$ level from January 4, 1996 to December 31, 2005. Two of the three subperiods display the same results as the whole period. The exception occurs in the second stage from 2000 to 2002, the I.T. bubble period, in which the variance risk premium is not distinguishable from zero.

Panels B and C of Table 2 report the summary statistics of variance risk premiums for 60 days and 90 days time to maturity respectively. The variance risk premiums are all significantly negative over the whole sample period. The negative variance risk premium for S\&P 500 index are also found by Engle (2004) and Carr and Wu (2009). The sub-period results are similar to those in Panel A for 30 days time to maturity, variance risk premium documented are averagely more negative than that of 30 days for 60 and 90 days time to maturity which is consistent with Bakshi and Kapadia (2003).

It is interesting to note that during the period 1996-1999 and 2002-2005 that the average return are positive and the variance risk premiums are negative. However, the variance risk premiums became positive during 2000-2002 while the average return is negative. This 
pattern is consistent with Bollerslev, Tauchen and Zhou (2009) which show that high (low) variance risk premia ${ }^{4}$ predicts high (low) future returns.

\subsection{Skewness risk premium}

Following the definition of the variance risk premium in Carr and Wu (2009), we define the skewness risk premium to be the return of a skewness swap which is a forward contract on the value of the third central moments. To ensure the swap rate in the contract is positive, we define the skewness risk premium as the negative difference between the physical and risk-neutral third central moments,

$$
S R P=E_{t}^{Q}\left[R_{t}-E_{t}^{Q}\left(R_{t}\right)\right]^{3}-E_{t}\left[R_{t}-E_{t}\left(R_{t}\right)\right]^{3}=M_{3}^{c Q}-M_{3}^{c} .
$$

From Equations (16) and (17), we know that the physical third central moment $M_{3}^{c}$ and risk-neutral third central moment $M_{3}^{c Q}$ can be obtained by

$$
\begin{aligned}
M_{3}^{c} & =\lambda_{1}\left(\kappa_{2}\right)^{3 / 2}=\lambda_{1} \sigma_{p}^{3}, \\
M_{3}^{c Q} & =\lambda_{1}^{Q}\left(\kappa_{2}^{Q}\right)^{3 / 2}=\lambda_{1}^{Q} \sigma_{r n}^{3} .
\end{aligned}
$$

Using the same method to compute the physical and risk-neutral central moments as in previous section, we obtain the time series of the realized and risk-neutral third central moments by Equations (37) and (38) for 30 days, 60 days and 90 days, respectively, time to maturity from January 4, 1996 to December 30, 2005.

Figures 3, 4 and 5 plot the daily dynamics of skewness risk premium, physical third central moments and risk-neutral central moments for 30,60 and 90 days time to maturity, respectively, from January 4, 1996 to December 30, 2005. The diamonds in these figures denote the skewness risk premiums and We observe that most of the diamonds is below zero line for the whole time horizon and for 30, 60 and 90 days time to maturity.

\footnotetext{
${ }^{4}$ The definition of variance risk premium in Bollerslev, Tauchen and Zhou (2009) is the difference between the risk-neutral and physical variance.
} 
Panels A, B and C of Table 3 report the skewness risk premiums for 30 days, 60 days and 90 days maturities for different subperiods from January 4, 1996 to December 30, 2005. The third and fourth columns are the mean of the physical and risk-neutral third central moments, the fifth column is the skewness risk premium estimation. The sixth column $\sigma_{\text {vrp }}$ gives the standard deviation of the estimated skewness risk premium and the last column is the t-statistics for the nonnegative skewness risk premium null-hypothesis, i.e, $H_{0}: \mu_{s r p} \geq 0$

We found that all the t-values in the last column of Table 3 are significantly negative. This means that the average skewness risk premium are significantly negative for the subperiods from January 4, 1996 to December 30, 2005 for 30, 60 and 90 days time to maturity. This is consistent with the literature that risk-neutral skewness is more negative than physical measure. Brunnermeier and Parker (2005), Brunnermeier, Gollier and Parker (2007) and Barberis and Huang (2007) show that investors' preference to skewness pushes up the prices of assets with high positive skewness, so that market portfolio has a negative skewness due to its well-diversified. Our empirical results match the observations in Bates (1991) and Rubinstein (1994) that index distributions have become (risk-neutrally) more negatively skewed after the crash of 1987.

We find that, in all three panels, the skewness risk premium is most negative during sub-period 2000-2002. Interestingly, it is also the sub-period in Table 1 where the average excess return is most negative.

\subsection{Kurtosis risk premium}

Following the definition of the skewness risk premium, we define the kurtosis risk premium to be the return of a kurtosis swap which is a forward contract on the value of the fourth central moment. That is

$$
K R P=E_{t}\left[R_{t}-E_{t}\left(R_{t}\right)\right]^{4}-E_{t}^{Q}\left[R_{t}-E_{t}^{Q}\left(R_{t}\right)\right]^{4}=M_{4}^{c}-M_{4}^{c Q}
$$


The fourth central moment can be obtained by equation (19):

$$
\begin{aligned}
M_{4}^{c} & =\lambda_{1}\left(\kappa_{2}\right)^{2}=\left(\lambda_{2}+3\right) \sigma_{p}^{4}, \\
M_{4}^{c Q} & =\lambda_{1}^{Q}\left(\kappa_{2}^{Q}\right)^{2}=\left(\lambda_{2}^{Q}+3\right) \sigma_{r n}^{4},
\end{aligned}
$$

and here 3 is added because $\lambda_{2}$ and $\lambda_{2}^{Q}$ are excess kurtosis in our definition.

From Equation (18) in Proposition 1 and Equation (41), it is easy to obtain risk-neutral fourth central moments. That is

$$
M_{4}^{c Q}=\left(24 \eta_{2}+3\right) \sigma_{r n}^{4} .
$$

The physical fourth central moment is directly calculated from the data based on the Equation (14). Figures 3,4 and 5 plot the time series, respectively, for the kurtosis risk premium, physical fourth central moments and risk-neutral fourth central moments for 30 days, 60 days and 90 days time to maturity from January 4, 1996 to December 30, 2005.

Table 4 shows the summary statistics of the kurtosis risk premium. Over the entire sample, we find that the kurtosis risk premium is not statistical distinguishable from zero for 30 days and 60 days time to maturities. However, the kurtosis risk premium for 90 days to maturity is significantly positive at a at the $10 \%$ level.

For different subperiods, the results are vary. For example, from January 3, 2000 to December 31, 2002, the average kurtosis risk premia for 30, 60 and 90 days time to maturity are all significantly positive. However, the kurtosis risk premium became significantly negative during the period from January 2, 2003 to December 30, 2005. The investors were likely to experience a loss when holding a constant long swap position during 2003-2005. Finding still suggests that kurtosis risk premium may not necessarily be zero, especially for long maturity contracts. 


\section{Conclusions}

It is well-known that risk-neutral moments have important effects on the option pricing. Bakshi, Kapadia and Madan (2003) point out that how to quantify the relationship between the risk-neutral density and moments of the physical return distribution is an outstanding issue. Motivated by Carr and $\mathrm{Wu}$ (2009), we propose a quantitative measurement for a skewness/kurtosis swap contract which longs a third/fourth central moments to capture the uncertainty of the skewness/kurtosis themselves.

The risk-neutral densities can be infered from options markets. We can approximate the swap rates of the skewness and kurtosis swap contracts by the risk-neutral third and fourth central moments respectively. By studying the difference between the physical and risk-neutral central moments, we can empirically investigate the variance risk premium, skewness risk premium and kurtosis risk premium using S\&P 500 index data based on a model-free manner.

We find that variance risk premium and skewness risk premium are all significantly negative for the time to maturities 30 days, 60 days and 90 days. The kurtosis risk premium is significantly positive for 90 days time to maturity, although it is not significant for 30 days and 60 days time to maturities.

This paper makes two contributions. First, this paper is the first to offer a justification and to propose the trading of the skewness swap and kurtosis swap contracts, which trade the forward realized third and fourth cumulants. Second, this is the first paper to document the signs and magnitudes of skewness and kurtosis premium. 


\section{References}

[1] Arditti, Fred D., 1967, Risk and the required return on equity, Journal of Fiannce 22, 19-36.

[2] Brunnermeier, Markus K., Christian Gollier and Jonathan A. Parker, 2007, Optimal beliefs, asset prices, and the preference for skewed returns, American Economic Review 97, 159-165.

[3] Bakshi, Gurdip, and Nikunj Kapadia, 2003, Delta-hedged gains and the negative market volatility risk premium, Review of Financial Studies 16, 527-566.

[4] Bakshi, Gurdip, Nikunj Kapadia, and Dilip Madan, 2003, Stock return characteristics, skew laws, and the differential pricing of individual equity options, Review of Financial Studies 16, 101-143.

[5] Bakshi, Gurdip and Dilip Madan, 2006, A theory of volatility spreads, Management Science 52, 1945-1956.

[6] Barberis, Nicholas and Ming Huang, 2007, Stocks as lotteries: the implication of probability weighting for security prices, Working paper, Yale University.

[7] Brunnermeier, Markus K. and Jonathan A. Parker, 2005, Optimal expectations, American Economic Review 95, 1092-1118.

[8] Bossu, Sebastien and Eva Strasser and Regis Guichard, May 2005, Just what you need to know about variance swaps Equity Derivatives, JPMorgan.

[9] Bollerslev, T., G. Tauchen and Hao Zhou, 2009, Expected stock returns and variance risk premia Review of Financial Studies, Forthcoming. 
[10] Bollerslev, T., and J. Wooldridge, 1988, A capital asset pricing model with timevarying covariances, Journal of Political Economics 96, 116-131.

[11] Carr, Peter, and Roger Lee, 2009, Robust replication of volatility derivatives, Working paper.

[12] Carr, Peter, and Dilip Madan, 1998, Towards a theory of volatility trading. In Robert Jarrow (Ed.), Volatility Estimation Techniques for Pricing Derivatives, 417-427, London: Risk Books.

[13] Carr, Peter, and Liuren Wu, 2003, What type of process underlies options? A simple robust test, Journal of Finance 58, 2581-2610.

[14] Carr, Peter, and Liuren Wu, 2007, Stochastic skew in currency options, Journal of Financial Economics 86, 213-247.

[15] Carr, Peter, and Liuren Wu, 2009, Variance risk premiums, Review of Financial Studies $22,1311-1341$.

[16] Conrad, Jennifer, Robert F. Dittmar and Eric Ghysels, 2008, Ex ante skewness and expected stock returns, Working paper.

[17] Coval, Joshua D., and Tyler Shumway, 2001, expected option returns, Journal of Finance 56, 983-1009.

[18] Demeterfi, Kresimir, Emaunuel Derman, Michael Kamal and Joseph Zou, 1999, A guide to volatility and variance swaps, Journal of Derivatives 6, 9-32.

[19] Dennis, Patrick, and Stewart Mayhew, 2002, Risk-neutral skewness: Evidence from stock options, Journal of Financial and Quantitative Analysis 37, 471-493. 
[20] Engle, R., and R. Robins, 1987, Estimating time varying risk premia in the term structure; The Arch-M model, Econometrica 55, 391-407.

[21] Engle, R., 2004, Risk and volatility: Econometric models and financial preactice, American Economic Review 94, 405-420.

[22] Eriksson, A., F. Forsberg and E. Ghysels, 2004, Approximating the probability distribution of functions of random variables: a new approach, Discussion paper, UNC.

[23] French, K., W. Schwert and R. Stambaugh, 1987, Expected stock returns and volatility, Journal of Financial Economics 19, 3-29.

[24] Harvey, Campbell R., and A. Siddique, 1999, Autoregressive conditional skewness, Journal of Financial and Quantitative Analysis 16, 527-566.

[25] Harvey, Campbell R., and A. Siddique, 2000, Time-varying conditional skewness and the market risk premium, Working paper.

[26] Horvath, P., and R. Scott, 1980, On the direction of preference for moments of higher order than the variance, Journal of Finance 35, 915-919.

[27] Jackwerth, J., 1999, Options implied risk-neutral distributions and implied binomial trees: a literature review, Journal of Derivatives 7, 66-82.

[28] Jackwerth, J., 2000, Recovering risk aversion from option prices and realized returns, Review of Financial Studies 13, 1611-1631.

[29] Kraus, A., and R. Litzenberger, 1976, Skewness preference and the valuation of risk assets, Journal of Finance 31, 1085-1100.

[30] Leland, H., 1980, Who should buy portfolio insurance, Journal of Finance 35, 581-594. 
[31] Mitton, Told, and Keith Vorkink, 2007, Equilibrium underdiversification and the preference for skewness, Review of Financial Studies 31, 1085-1100.

[32] Rubinstein, Mark, 1994, Implied binomial trees, Journal of Finance 20, 1255-1288.

[33] Scott, Robert C., and Philip A. Horvath , 1980, On the direction of preference ofr moments of higher order than the variance, Journal of Finance 35, 915-919.

[34] Whaley, R.E., 2002, Return and risk CBOE buy right monthly index, Journal of Derivatives 10, 35-42.

[35] Zhang, Jin E., Yi Xiang, 2008, The implied volatility smirk, Quantitative Finance 8, 263-284. 
Table 1: The Average Excess Return

This table provides the annualized equity premium $\phi$ from January 4, 1996 to December 30,2005 which is calculated by $\phi=\mu-r$. The data frequency is $\Delta=\frac{1}{252}$ (one day) and $\mu$ is the average historical return of the sample used, and $\mathrm{r}$ is the corresponding average risk-free rate. Here $\mathrm{r}$ is the average 1-month US yield. $\mu$ is computed by the following

$$
\mu=252 \times \frac{1}{n-1} \sum_{i=1}^{n-1} \ln \left(S_{t+d t} / S_{t}\right)
$$

$\hat{\sigma}$ is the standard deviations of the sample and $\mathrm{n}$ is number of the observations of the sample. SR is the sharp ratio which is defined by $S R=\phi / \hat{\sigma}$. All the results in the table are based on annual adjustment.

\begin{tabular}{llclclc}
\hline Sample Period & Obs. & $\mu$ & $\mathrm{r}$ & $\phi$ & $\hat{\sigma}$ & $\mathrm{SR}$ \\
\hline $1996 / 01 / 04-2005 / 12 / 30$ & 2516 & 0.0867 & 0.0362 & 0.0505 & 0.1833 & 0.2755 \\
\hline $1996 / 01 / 04-1999 / 12 / 31$ & 1008 & 0.2320 & 0.0499 & 0.1821 & 0.1737 & 1.0484 \\
$2000 / 01 / 03-2002 / 12 / 31$ & 752 & -0.1446 & 0.0370 & -0.1446 & 0.2333 & -0.6198 \\
$2003 / 01 / 02-2005 / 12 / 30$ & 756 & 0.1253 & 0.0153 & 0.1100 & 0.1316 & 0.8359 \\
\hline $1996 / 01 / 04-1996 / 12 / 31$ & 252 & 0.1828 & 0.0512 & 0.1316 & 0.1181 & 1.1143 \\
$1997 / 01 / 02-1997 / 12 / 31$ & 253 & 0.2856 & 0.0518 & 0.2338 & 0.1813 & 1.2896 \\
$1998 / 01 / 02-1998 / 12 / 31$ & 252 & 0.2571 & 0.0489 & 0.2082 & 0.2029 & 1.0261 \\
$1999 / 01 / 04-1999 / 12 / 31$ & 251 & 0.1947 & 0.0476 & 0.1471 & 0.1807 & 0.8141 \\
\hline $2000 / 01 / 03-2000 / 12 / 29$ & 252 & -0.0823 & 0.0597 & -0.1420 & 0.2222 & -0.6391 \\
$2001 / 01 / 02-2001 / 12 / 31$ & 248 & -0.1188 & 0.0350 & -0.1538 & 0.2156 & -0.7134 \\
$2002 / 01 / 02-2002 / 12 / 31$ & 252 & -0.2324 & 0.0162 & -0.2486 & 0.2603 & -0.9551 \\
\hline $2003 / 01 / 02-2003 / 12 / 31$ & 252 & 0.2487 & 0.0102 & 0.2385 & 0.1707 & 1.3972 \\
$2004 / 01 / 02-2004 / 12 / 31$ & 252 & 0.0923 & 0.0127 & 0.0796 & 0.1109 & 0.7178 \\
$2005 / 01 / 03-2005 / 12 / 30$ & 252 & 0.0348 & 0.0230 & 0.0118 & 0.1028 & 0.1148 \\
\hline
\end{tabular}


Table 2: Variance Risk Premiums

This table reports the summary statistics of variance risk premiums from January 4, 1996 to December 30, 2005. Panel A, B and C report them respectively for 30, 60 and 90 days time to maturity. Physical variance is calculated by realized return and risk-neutral variance is implied from options. The variance risk premium is defined by the difference between the former two variances. $\mu_{p h y}$ is the mean of the physical variance, $\mu_{r n}$ is the mean of the risk-neutral variance, $\mu_{v r p}$ and $\sigma_{v r p}$ are the mean and standard deviation of variance risk premium. $*, * *$ and $* * *$ means significance at $90 \%, 95 \%$ and $99 \%$ confidence levels for T-test respectively.

Panel A: variance risk premium for 30 days time to maturity

\begin{tabular}{llccccc}
\hline Sample Period & Obs. & $\mu_{\text {phy }}$ & $\mu_{\text {rn }}$ & $\mu_{\text {vrp }}$ & $\sigma_{\text {vrp }}$ & t-value \\
\hline $1996 / 01 / 04-2005 / 12 / 30$ & 2516 & 0.0339 & 0.0397 & -0.0058 & 0.0252 & $-11.51^{* * *}$ \\
\hline $1996 / 01 / 04-1999 / 12 / 31$ & 1008 & 0.0311 & 0.0399 & -0.0088 & 0.0265 & $-10.56^{* * *}$ \\
$2000 / 01 / 03-2002 / 12 / 31$ & 752 & 0.0550 & 0.0544 & 0.0006 & 0.0318 & 0.5017 \\
$2003 / 01 / 02-2005 / 12 / 30$ & 756 & 0.0168 & 0.0248 & -0.0080 & 0.0103 & $-21.41^{* * *}$ \\
\hline $1996 / 01 / 04-1996 / 12 / 31$ & 252 & 0.0137 & 0.0209 & -0.0072 & 0.0087 & $-13.09^{* * *}$ \\
$1997 / 01 / 02-1997 / 12 / 31$ & 253 & 0.0343 & 0.0409 & -0.0066 & 0.0312 & $-3.36^{* * *}$ \\
$1998 / 01 / 02-1998 / 12 / 31$ & 252 & 0.0417 & 0.0515 & -0.0098 & 0.0399 & $-3.90^{* * *}$ \\
$1999 / 01 / 04-1999 / 12 / 31$ & 252 & 0.0347 & 0.0463 & -0.0117 & 0.0124 & $-12.91^{* * *}$ \\
$2000 / 01 / 03-2000 / 12 / 29$ & 252 & 0.0518 & 0.0450 & 0.0068 & 0.0228 & $4.75^{* * *}$ \\
$2001 / 01 / 02-2001 / 12 / 31$ & 248 & 0.0424 & 0.0531 & -0.0107 & 0.0230 & $-5.61^{* * *}$ \\
$2002 / 01 / 02-2002 / 12 / 31$ & 252 & 0.0705 & 0.0651 & 0.0054 & 0.0380 & $2.27^{* * *}$ \\
$2003 / 01 / 02-2003 / 12 / 31$ & 252 & 0.0271 & 0.0429 & -0.0158 & 0.0128 & $-19.56^{* * *}$ \\
$2004 / 01 / 02-2004 / 12 / 31$ & 252 & 0.0124 & 0.0189 & -0.0065 & 0.0057 & $-18.15^{* * *}$ \\
$2005 / 01 / 03-2005 / 12 / 30$ & 252 & 0.0108 & 0.0127 & -0.0018 & 0.0048 & $-6.12^{* * *}$ \\
\hline
\end{tabular}


Table 2 (continued)

\begin{tabular}{lllllll}
\hline \multicolumn{1}{l}{ Panel B: variance risk premium for 60 days time to maturity } & & \\
\hline Sample Period & Obs. & $\mu_{p h y}$ & $\mu_{r n}$ & $\mu_{v r p}$ & $\sigma_{v r p}$ & t-value \\
\hline $1996 / 01 / 04-2005 / 12 / 30$ & 2513 & 0.0338 & 0.0408 & -0.0070 & 0.0240 & $-14.66^{* * *}$ \\
\hline $1996 / 01 / 04-1999 / 12 / 31$ & 1005 & 0.0313 & 0.0427 & -0.0114 & 0.0241 & $-15.02^{* * *}$ \\
$2000 / 01 / 03-2002 / 12 / 31$ & 752 & 0.0549 & 0.0528 & 0.0021 & 0.0307 & $1.85^{* *}$ \\
$2003 / 01 / 02-2005 / 12 / 30$ & 756 & 0.0162 & 0.0264 & -0.0102 & 0.0091 & $-30.89^{* * *}$ \\
\hline $1996 / 01 / 04-1996 / 12 / 31$ & 252 & 0.0140 & 0.0215 & -0.0075 & 0.0072 & $-16.41^{* * *}$ \\
$1997 / 01 / 02-1997 / 12 / 31$ & 253 & 0.0342 & 0.0421 & -0.0078 & 0.0201 & $-6.20^{* * *}$ \\
$1998 / 01 / 02-1998 / 12 / 31$ & 252 & 0.0425 & 0.0552 & -0.0127 & 0.0402 & $-5.01^{* * *}$ \\
$1999 / 01 / 04-1999 / 12 / 31$ & 252 & 0.0341 & 0.0517 & -0.0176 & 0.0135 & $-20.71^{* * *}$ \\
$2000 / 01 / 03-2000 / 12 / 29$ & 252 & 0.0504 & 0.0442 & 0.0062 & 0.0208 & $4.77^{* * *}$ \\
$2001 / 01 / 02-2001 / 12 / 31$ & 248 & 0.0433 & 0.0514 & -0.0081 & 0.0269 & $-4.76^{* * *}$ \\
$2002 / 01 / 02-2002 / 12 / 31$ & 252 & 0.0707 & 0.0628 & 0.0080 & 0.0390 & $3.24^{* * *}$ \\
$2003 / 01 / 02-2003 / 12 / 31$ & 252 & 0.0255 & 0.0439 & -0.0184 & 0.0096 & $-30.41^{* * *}$ \\
$2004 / 01 / 02-2004 / 12 / 31$ & 252 & 0.0124 & 0.0212 & -0.0089 & 0.0046 & $-30.49^{* * *}$ \\
$2005 / 01 / 03-2005 / 12 / 30$ & 252 & 0.0108 & 0.0140 & -0.0033 & 0.0040 & $-13.05^{* * *}$ \\
\hline
\end{tabular}


Table 2 (continued)

\begin{tabular}{lllllll}
\hline \multicolumn{2}{l}{ Panel C: variance risk premium for 90 days time to maturity } & & \\
\hline Sample Period & Obs. & $\mu_{p h y}$ & $\mu_{r n}$ & $\mu_{v r p}$ & $\sigma_{v r p}$ & t-value \\
\hline $1996 / 01 / 04-2005 / 12 / 30$ & 2513 & 0.0337 & 0.0410 & -0.0073 & 0.0232 & $-15.83^{* * *}$ \\
\hline $1996 / 01 / 04-1999 / 12 / 31$ & 1005 & 0.0317 & 0.0436 & -0.0120 & 0.0228 & $-16.63^{* * *}$ \\
$2000 / 01 / 03-2002 / 12 / 31$ & 752 & 0.0547 & 0.0512 & 0.0035 & 0.0291 & $3.27^{* * *}$ \\
$2003 / 01 / 02-2005 / 12 / 30$ & 756 & 0.0154 & 0.0273 & -0.0118 & 0.0091 & $-35.93^{* * *}$ \\
\hline $1996 / 01 / 04-1996 / 12 / 31$ & 249 & 0.0140 & 0.0215 & -0.0076 & 0.0061 & $-19.45^{* * *}$ \\
$1997 / 01 / 02-1997 / 12 / 31$ & 253 & 0.0339 & 0.0416 & -0.0077 & 0.0171 & $-7.18^{* * *}$ \\
$1998 / 01 / 02-1998 / 12 / 31$ & 252 & 0.0437 & 0.0565 & -0.0129 & 0.0382 & $-5.35^{* * *}$ \\
$1999 / 01 / 04-1999 / 12 / 31$ & 251 & 0.0349 & 0.0547 & -0.0198 & 0.0142 & $-22.12^{* * *}$ \\
$2000 / 01 / 03-2000 / 12 / 29$ & 252 & 0.0496 & 0.0440 & 0.0057 & 0.0189 & $4.77^{* * *}$ \\
$2001 / 01 / 02-2001 / 12 / 31$ & 248 & 0.0427 & 0.0497 & -0.0069 & 0.0225 & $-4.84^{* * *}$ \\
$2002 / 01 / 02-2002 / 12 / 31$ & 252 & 0.0715 & 0.0600 & 0.0115 & 0.0388 & $4.70^{* * *}$ \\
$2003 / 01 / 02-2003 / 12 / 31$ & 252 & 0.0236 & 0.0438 & -0.0202 & 0.0095 & $-33.65^{* * *}$ \\
$2004 / 01 / 02-2004 / 12 / 31$ & 252 & 0.0121 & 0.0228 & -0.0107 & 0.0042 & $-40.25^{* * *}$ \\
$2005 / 01 / 03-2005 / 12 / 30$ & 252 & 0.0106 & 0.0152 & -0.0046 & 0.0037 & $-19.67^{* * *}$ \\
\hline
\end{tabular}


Table 3: Skewness Risk Premiums

This table reports the estimated skewness risk premiums from January 4, 1996 to December 30, 2005. Panel A, B and C report them respectively for 30, 60 and 90 days time to maturity. Risk-neutral skewness is implied from options and physical skewness is calculated by realized return and. The skewness risk premium is defined by the difference between the former two skewness. $\mu_{p h y}$ is the mean of the physical skewness, $\mu_{r n}$ is the mean of the risk-neutral skewness, $\mu_{s r p}$ and $\sigma_{s r p}$ are the mean and standard deviation of skewness risk premium. $*, * *$ and $* * *$ means significance at $90 \%, 95 \%$ and $99 \%$ confidence levels for T-test respectively.

Panel A: skewness risk premium for 30 days time to maturity

\begin{tabular}{llccccc}
\hline Sample Period & Obs. & $\mu_{\text {phy }}$ & $\mu_{r n}$ & $\mu_{v r p}$ & $\sigma_{v r p}$ & t-value \\
\hline $1996 / 01 / 04-2005 / 12 / 30$ & 2516 & 0.0007 & -0.0095 & -0.0101 & 0.0156 & $-32.48^{* * *}$ \\
\hline $1996 / 01 / 04-1999 / 12 / 31$ & 1008 & -0.0014 & -0.0115 & -0.0101 & 0.0167 & $-19.11^{* * *}$ \\
$2000 / 01 / 03-2002 / 12 / 31$ & 752 & 0.0041 & -0.0124 & -0.0165 & 0.0183 & $-24.74^{* * *}$ \\
$2003 / 01 / 02-2005 / 12 / 30$ & 756 & 0.00006 & -0.0037 & -0.0038 & 0.0050 & $-20.82^{* * *}$ \\
\hline $1996 / 01 / 04-1996 / 12 / 31$ & 252 & -0.0008 & -0.0034 & -0.0026 & 0.0023 & $-17.78^{* * *}$ \\
$1997 / 01 / 02-1997 / 12 / 31$ & 253 & -0.0029 & -0.0094 & -0.0065 & 0.0141 & $-7.33^{* * *}$ \\
$1998 / 01 / 02-1998 / 12 / 31$ & 252 & -0.0020 & -0.0206 & -0.0186 & 0.0269 & $-10.98^{* * *}$ \\
$1999 / 01 / 04-1999 / 12 / 31$ & 251 & 0.00004 & -0.0126 & -0.0126 & 0.0069 & $-28.96^{* * *}$ \\
$2000 / 01 / 03-2000 / 12 / 29$ & 252 & -0.0028 & -0.0084 & -0.0056 & 0.0110 & $-16.18^{* * *}$ \\
$2001 / 01 / 02-2001 / 12 / 31$ & 248 & -0.000006 & -0.0115 & -0.0115 & 0.0110 & $-16.58^{* * *}$ \\
$2002 / 01 / 02-2002 / 12 / 31$ & 252 & 0.0094 & -0.0174 & -0.0268 & 0.0246 & $-17.28^{* * *}$ \\
$2003 / 01 / 02-2003 / 12 / 31$ & 252 & 0.0002 & -0.0073 & -0.0075 & 0.0072 & $-16.59^{* * *}$ \\
$2004 / 01 / 02-2004 / 12 / 31$ & 252 & -0.00006 & -0.0025 & -0.0024 & 0.0012 & $-31.14^{* * *}$ \\
$2005 / 01 / 03-2005 / 12 / 30$ & 252 & 0.00003 & -0.0014 & -0.0014 & 0.0009 & $-25.83^{* * *}$ \\
\hline
\end{tabular}


Table 3 (continued)

\begin{tabular}{llccccc}
\hline \multicolumn{1}{l}{ Panel B: skewness risk premium for 60 days time to maturity } & & \\
\hline Sample Period & Obs. & $\mu_{p h y}$ & $\mu_{r n}$ & $\mu_{v r p}$ & $\sigma_{v r p}$ & t-value \\
\hline $1996 / 01 / 04-2005 / 12 / 30$ & 2513 & 0.0006 & -0.0108 & -0.0114 & 0.0141 & $-40.58^{\star}$ \\
\hline $1996 / 01 / 04-1999 / 12 / 31$ & 1005 & -0.0017 & -0.0136 & -0.0120 & 0.0162 & $-23.46^{\star}$ \\
$2000 / 01 / 03-2002 / 12 / 31$ & 752 & 0.0042 & -0.0132 & -0.0173 & 0.0143 & $-33.23^{\star}$ \\
$2003 / 01 / 02-2005 / 12 / 30$ & 756 & 0.00005 & -0.0048 & -0.0049 & 0.0059 & $-22.71^{\star}$ \\
\hline $1996 / 01 / 04-1996 / 12 / 31$ & 249 & -0.0008 & -0.0038 & -0.0030 & 0.0024 & $-20.09^{* * *}$ \\
$1997 / 01 / 02-1997 / 12 / 31$ & 253 & -0.0032 & -0.0100 & -0.0067 & 0.0111 & $-9.66^{* * *}$ \\
$1998 / 01 / 02-1998 / 12 / 31$ & 252 & -0.0023 & -0.0236 & -0.0213 & 0.0250 & $-13.54^{* * *}$ \\
$1999 / 01 / 04-1999 / 12 / 31$ & 251 & -0.0003 & -0.0170 & -0.0167 & 0.0086 & $-30.84^{* * *}$ \\
$2000 / 01 / 03-2000 / 12 / 29$ & 252 & 0.0028 & -0.0094 & -0.0122 & 0.0070 & $-27.52^{* * *}$ \\
$2001 / 01 / 02-2001 / 12 / 31$ & 248 & -0.0005 & -0.0121 & -0.0116 & 0.0087 & $-21.05^{* * *}$ \\
$2002 / 01 / 02-2002 / 12 / 31$ & 252 & 0.0101 & -0.0181 & -0.0281 & 0.0177 & $-25.23^{* * *}$ \\
$2003 / 01 / 02-2003 / 12 / 31$ & 252 & 0.0002 & -0.0093 & -0.0095 & 0.0082 & $-18.36^{* * *}$ \\
$2004 / 01 / 02-2004 / 12 / 31$ & 252 & -0.0001 & -0.0034 & -0.0033 & 0.0015 & $-34.23^{* * *}$ \\
$2005 / 01 / 03-2005 / 12 / 30$ & 252 & 0.00002 & -0.0017 & -0.0007 & 0.0009 & $-37.93^{* * *}$ \\
\hline
\end{tabular}


Table 3 (continued)

\begin{tabular}{llccccc}
\hline Panel C: skewness risk premium for & 90 days time to maturity & & \\
\hline Sample Period & Obs. & $\mu_{p h y}$ & $\mu_{r n}$ & $\mu_{v r p}$ & $\sigma_{\text {vrp }}$ & t-value \\
\hline $1996 / 01 / 04-1999 / 12 / 31$ & 1005 & -0.0018 & -0.0150 & -0.0132 & 0.0183 & $-22.84^{* * *}$ \\
$2000 / 01 / 03-2002 / 12 / 31$ & 752 & 0.0041 & -0.0126 & -0.0167 & 0.0117 & $-39.28^{* * *}$ \\
$2003 / 01 / 02-2005 / 12 / 30$ & 756 & -0.000003 & -0.0052 & -0.0052 & 0.0053 & $-26.78^{* * *}$ \\
\hline $1996 / 01 / 04-1996 / 12 / 31$ & 249 & -0.0007 & -0.0044 & -0.0037 & 0.0025 & $-22.96^{* * *}$ \\
$1997 / 01 / 02-1997 / 12 / 31$ & 253 & -0.0032 & -0.0100 & -0.0068 & 0.0100 & $-10.85^{* * *}$ \\
$1998 / 01 / 02-1998 / 12 / 31$ & 252 & -0.0029 & -0.0248 & -0.0219 & 0.0243 & $-14.31^{* * *}$ \\
$1999 / 01 / 04-1999 / 12 / 31$ & 251 & -0.0003 & -0.0205 & -0.0202 & 0.0196 & $-16.33^{* * *}$ \\
$2000 / 01 / 03-2000 / 12 / 29$ & 252 & 0.0024 & -0.0097 & 0.0121 & 0.0050 & $-38.65^{* * *}$ \\
$2001 / 01 / 02-2001 / 12 / 31$ & 248 & -0.0003 & -0.0145 & -0.0112 & 0.0068 & $-26.05^{* * *}$ \\
$2002 / 01 / 02-2002 / 12 / 31$ & 252 & 0.0101 & -0.0166 & -0.0267 & 0.0136 & $-31.21^{* * *}$ \\
$2003 / 01 / 02-2003 / 12 / 31$ & 252 & 0.00009 & -0.0094 & -0.0095 & 0.0071 & $-21.16^{* * *}$ \\
$2004 / 01 / 02-2004 / 12 / 31$ & 252 & -0.0001 & -0.0039 & -0.0038 & 0.0017 & $-35.91^{* * *}$ \\
$2005 / 01 / 03-2005 / 12 / 30$ & 252 & $1.42 \mathrm{E}-7$ & -0.0021 & -0.0021 & 0.0007 & $-45.98^{* * *}$ \\
\hline
\end{tabular}


Table 4: Kurtosis Risk Premiums

This table reports the summary statistics of kurtosis risk premiums from January 4, 1996 to December 30, 2005. Panel A, B and C report them respectively for 30, 60 and 90 days time to maturity. Physical kurtosis is calculated by realized return and risk-neutral kurtosis is implied from options. The kurtosis risk premium is defined by the difference between the former two skewness. $\mu_{p h y}$ is the mean of the physical kurtosis, $\mu_{r n}$ is the mean of the risk-neutral kurtosis, $\mu_{s r p}$ and $\sigma_{s r p}$ are the mean and standard deviation of kurtosis risk premium. $*, * *$ and $* * *$ means significance at $90 \%, 95 \%$ and $99 \%$ confidence levels for T-test respectively.

Panel A: kurtosis risk premium for 30 days time to maturity

\begin{tabular}{llccccc}
\hline Sample Period & Obs. & $\mu_{\text {phy }}$ & $\mu_{r n}$ & $\mu_{v r p}$ & $\sigma_{v r p}$ & t-value \\
\hline $1996 / 01 / 04-2005 / 12 / 30$ & 2516 & 0.0077 & 0.0074 & 0.0003 & 0.0187 & 0.8285 \\
\hline $1996 / 01 / 04-1999 / 12 / 31$ & 1008 & 0.0078 & 0.0065 & 0.0013 & 0.0236 & $1.83^{* *}$ \\
$2000 / 01 / 03-2002 / 12 / 31$ & 752 & 0.0139 & 0.0126 & 0.0013 & 0.0201 & $1.78^{* *}$ \\
$2003 / 01 / 02-2005 / 12 / 30$ & 756 & 0.0013 & 0.0034 & -0.0021 & 0.0046 & $-12.33^{* * *}$ \\
\hline $1996 / 01 / 04-1996 / 12 / 31$ & 252 & 0.0010 & 0.0015 & -0.0006 & 0.0014 & $-6.40^{* * *}$ \\
$1997 / 01 / 02-1997 / 12 / 31$ & 253 & 0.0119 & 0.0059 & 0.0060 & 0.0320 & $3.00^{* * *}$ \\
$1998 / 01 / 02-1998 / 12 / 31$ & 252 & 0.0142 & 0.0112 & 0.0029 & 0.0335 & $1.38^{*}$ \\
$1999 / 01 / 04-1999 / 12 / 31$ & 251 & 0.0042 & 0.0072 & -0.0030 & 0.0048 & $-9.85^{* * *}$ \\
$2000 / 01 / 03-2000 / 12 / 29$ & 252 & 0.0136 & 0.0074 & 0.0062 & 0.0150 & $6.55^{* * *}$ \\
$2001 / 01 / 02-2001 / 12 / 31$ & 248 & 0.0081 & 0.0116 & -0.0035 & 0.0141 & $-3.96^{* * *}$ \\
$2002 / 01 / 02-2002 / 12 / 31$ & 252 & 0.0200 & 0.0189 & 0.0012 & 0.0272 & 0.68 \\
$2003 / 01 / 02-2003 / 12 / 31$ & 252 & 0.0031 & 0.0083 & -0.0052 & 0.0070 & $-11.85^{* * *}$ \\
$2004 / 01 / 02-2004 / 12 / 31$ & 252 & 0.0005 & 0.0013 & -0.0008 & 0.0007 & $-18.59^{* * *}$ \\
$2005 / 01 / 03-2005 / 12 / 30$ & 252 & 0.0004 & 0.0006 & -0.0002 & 0.0004 & $-7.72^{* * *}$ \\
\hline
\end{tabular}


Table 4 (continued)

\begin{tabular}{lllllll}
\hline \multicolumn{7}{l}{ Panel B: kurtosis risk premium for 60 days time to maturity } \\
\hline Sample Period & Obs. & $\mu_{\text {phy }}$ & $\mu_{r n}$ & $\mu_{\text {vrp }}$ & $\sigma_{v r p}$ & t-value \\
\hline $1996 / 01 / 04-2005 / 12 / 30$ & 2513 & 0.0073 & 0.0073 & 0.00005 & 0.0142 & 0.1907 \\
\hline $1996 / 01 / 04-1999 / 12 / 31$ & 1005 & 0.0073 & 0.0071 & 0.0002 & 0.0167 & 0.4858 \\
$2000 / 01 / 03-2002 / 12 / 31$ & 752 & 0.0134 & 0.0113 & 0.0021 & 0.0166 & $3.52^{* * *}$ \\
$2003 / 01 / 02-2005 / 12 / 30$ & 756 & 0.0012 & 0.0035 & -0.0023 & 0.0040 & $-15.72^{* * *}$ \\
\hline $1996 / 01 / 04-1996 / 12 / 31$ & 249 & 0.0009 & 0.0016 & -0.0007 & 0.0012 & $-9.21^{* * *}$ \\
$1997 / 01 / 02-1997 / 12 / 31$ & 253 & 0.0110 & 0.0063 & 0.0047 & 0.0195 & $3.83^{* * *}$ \\
$1998 / 01 / 02-1998 / 12 / 31$ & 252 & 0.0132 & 0.0118 & 0.0014 & 0.0257 & -0.89 \\
$1999 / 01 / 04-1999 / 12 / 31$ & 251 & 0.0040 & 0.0085 & -0.0045 & 0.0055 & $-13.01^{* * *}$ \\
$2000 / 01 / 03-2000 / 12 / 29$ & 252 & 0.0128 & -0.0067 & 0.0060 & 0.0109 & $8.76^{* * *}$ \\
$2001 / 01 / 02-2001 / 12 / 31$ & 248 & 0.0081 & 0.0104 & -0.0022 & 0.0115 & $-3.06^{* * *}$ \\
$2002 / 01 / 02-2002 / 12 / 31$ & 252 & 0.0193 & 0.0168 & 0.0025 & 0.0233 & $1.72^{* *}$ \\
$2003 / 01 / 02-2003 / 12 / 31$ & 252 & 0.0028 & 0.0082 & -0.0054 & 0.0057 & $-15.13^{* * *}$ \\
$2004 / 01 / 02-2004 / 12 / 31$ & 252 & 0.0004 & -0.0016 & -0.0011 & 0.0006 & $-27.28^{* * *}$ \\
$2005 / 01 / 03-2005 / 12 / 30$ & 252 & 0.0004 & 0.0007 & -0.0003 & 0.0003 & $-14.59^{* * *}$ \\
\hline
\end{tabular}


Table 4 (continued)

\begin{tabular}{llllllc}
\hline \multicolumn{7}{l}{ Panel C: kurtosis risk premium for 90 days time to maturity } \\
\hline Sample Period & Obs. & $\mu_{\text {phy }}$ & $\mu_{r n}$ & $\mu_{\text {vrp }}$ & $\sigma_{\text {vrp }}$ & t-value \\
\hline $1996 / 01 / 04-2005 / 12 / 30$ & 2513 & 0.0071 & 0.0067 & 0.0004 & 0.0143 & $1.46^{*}$ \\
\hline $1996 / 01 / 04-1999 / 12 / 31$ & 1005 & 0.0073 & 0.0065 & 0.0008 & 0.0183 & $1.32^{*}$ \\
$2000 / 01 / 03-2002 / 12 / 31$ & 752 & 0.0131 & 0.0103 & 0.0028 & 0.0144 & $5.30^{* * *}$ \\
$2003 / 01 / 02-2005 / 12 / 30$ & 756 & 0.0010 & 0.0034 & -0.0024 & 0.0037 & $-17.74^{* * *}$ \\
\hline $1996 / 01 / 04-1996 / 12 / 31$ & 249 & 0.0009 & 0.0014 & -0.0006 & 0.0010 & $-9.03^{* * *}$ \\
$1997 / 01 / 02-1997 / 12 / 31$ & 253 & 0.0105 & 0.0056 & 0.0049 & 0.0170 & $4.62^{* * *}$ \\
$1998 / 01 / 02-1998 / 12 / 31$ & 252 & 0.032 & 0.0112 & 0.0021 & 0.0215 & $1.54^{*}$ \\
$1999 / 01 / 04-1999 / 12 / 31$ & 251 & 0.0044 & 0.0078 & -0.0035 & 0.0235 & $-2.33^{* * *}$ \\
$2000 / 01 / 03-2000 / 12 / 29$ & 252 & 0.0122 & 0.0066 & 0.0056 & 0.0085 & $10.43^{* * *}$ \\
$2001 / 01 / 02-2001 / 12 / 31$ & 248 & 0.0079 & 0.0094 & -0.0015 & 0.0095 & $-2.48^{* * *}$ \\
$2002 / 01 / 02-2002 / 12 / 31$ & 252 & 0.0191 & 0.0149 & 0.0042 & 0.0207 & $3.20^{* * *}$ \\
$2003 / 01 / 02-2003 / 12 / 31$ & 252 & 0.0023 & 0.0077 & -0.0054 & 0.0052 & $-16.63^{* * *}$ \\
$2004 / 01 / 02-2004 / 12 / 31$ & 252 & 0.0004 & 0.0018 & -0.0014 & 0.0007 & $-30.61^{* * *}$ \\
$2005 / 01 / 03-2005 / 12 / 30$ & 252 & 0.0004 & 0.0008 & -0.0004 & 0.0003 & $-20.56^{* * *}$ \\
\hline
\end{tabular}


Figure 1: Time series of daily closing levels of the S\&P 500 index from January 4, 1996 to December 30, 2005.

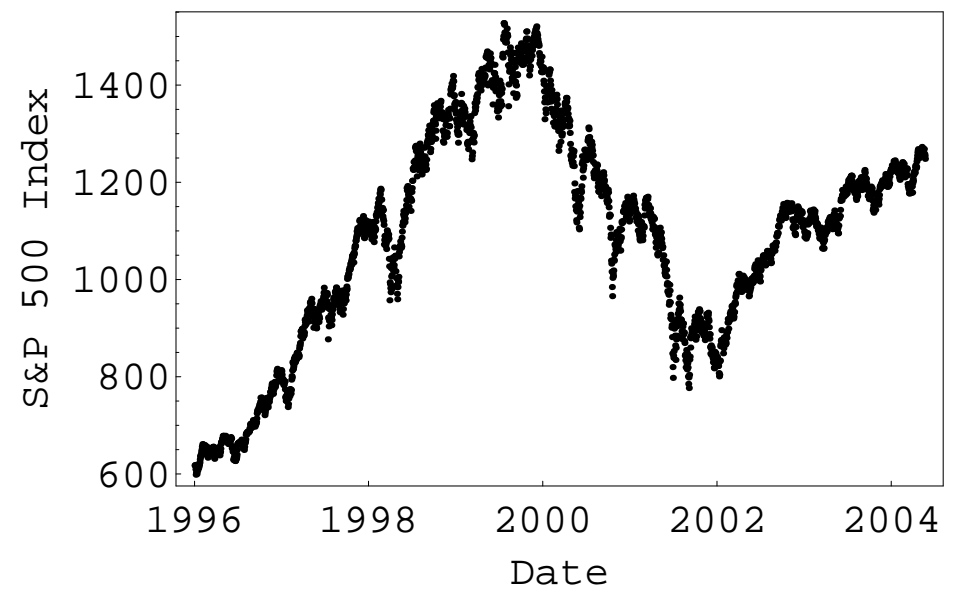


Figure 2: The implied volatility smirks with 15-day and 43-day time to maturities The following figures show that the implied volatility smirks on September 6, 2002 for options with maturities 15 days and 43 days respectively on September 21, 2002. The larger dots are the implied volatilities computed from the market prices of the out-ofmoney calls and puts. The solid line is generated by fitting the market implied volatility with a quadratic function that passes through the point at the money and minimizes the volume-weighted mean square errors of the implied volatility. The vertical lines are the trading volumes normalized by 20,000 contracts for the corresponding traded on September 6 , 2002. The fitted quadratic functions for 15 days and 43 days respectively are: 0.3128(1$\left.0.1614 x+0.0106 x^{2}\right)$ and $0.3181\left(1-0.2274 x+0.0095 x^{2}\right)$.
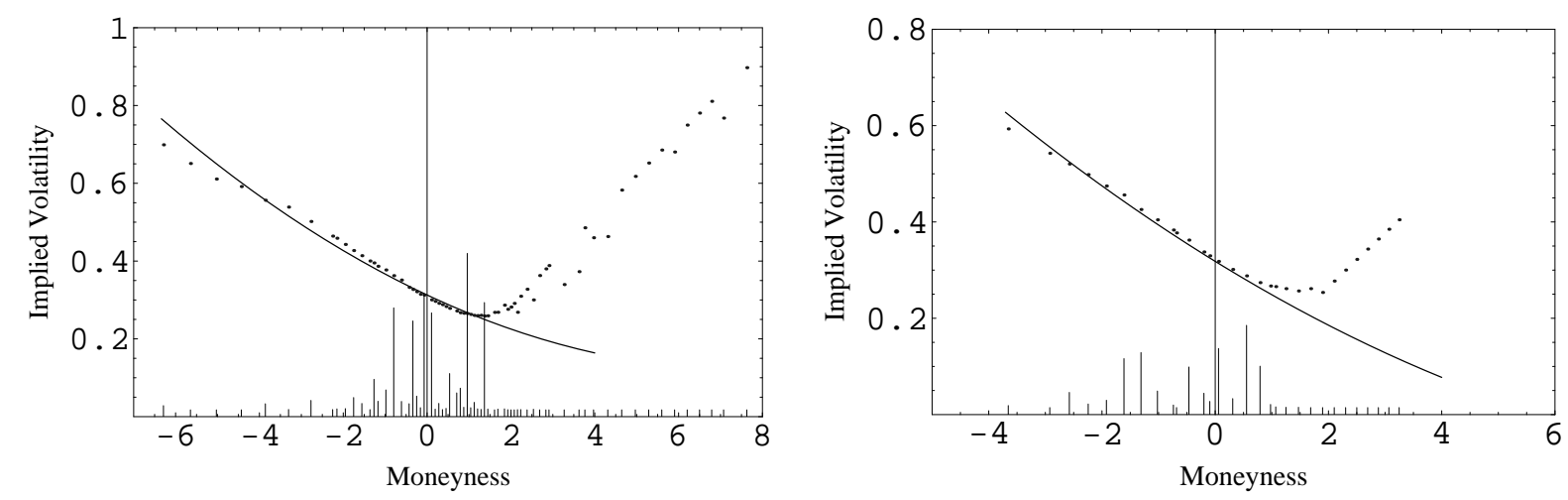
Figure 3: The variance, skewness and kurtosis risk premium for 30 days The figures plot respectively the daily changes of the second/variance risk premium, third/skewness risk premium, fourth/kurtosis risk premium(diamond points), the physical second/variance, third/skewness and fourth/kurtosis central moments (darkest triangle points) and the risk-neutral second/variance, third/skewness and fourth/kurtosis central moments (unfilled star points) from January 4, 1996 to December 30, 2005 for 30 days time to maturity. The variance/skewness/kurtosis risk premium is defined by the positive/negative/positive difference between the physical second/third/fourth central moments and the risk-neutral second/third/fourth central moments.
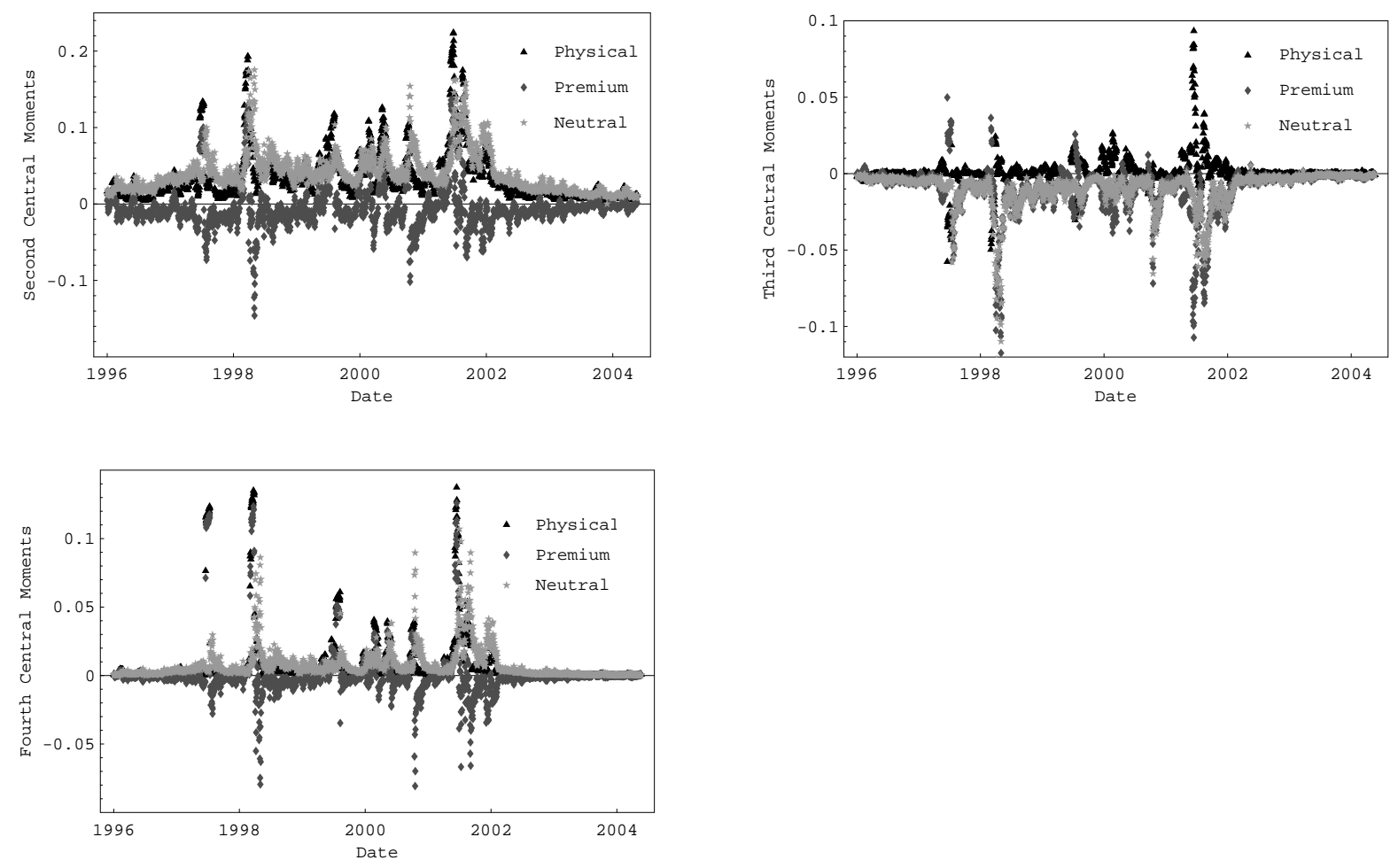
Figure 4: The variance, skewness and kurtosis risk premium for 60 days The figures plot respectively the daily changes of the second/variance risk premium, third/skewness risk premium, fourth/kurtosis risk premium(diamond points), the physical second/variance, third/skewness and fourth/kurtosis central moments (darkest triangle points) and the risk-neutral second/variance, third/skewness and fourth/kurtosis central moments (unfilled star points) from January 4, 1996 to December 30, 2005 for 60 days time to maturity. The variance/skewness/kurtosis risk premium is defined by the positive/negative/positive difference between the physical second/third/fourth central moments and the risk-neutral second/third/fourth central moments.
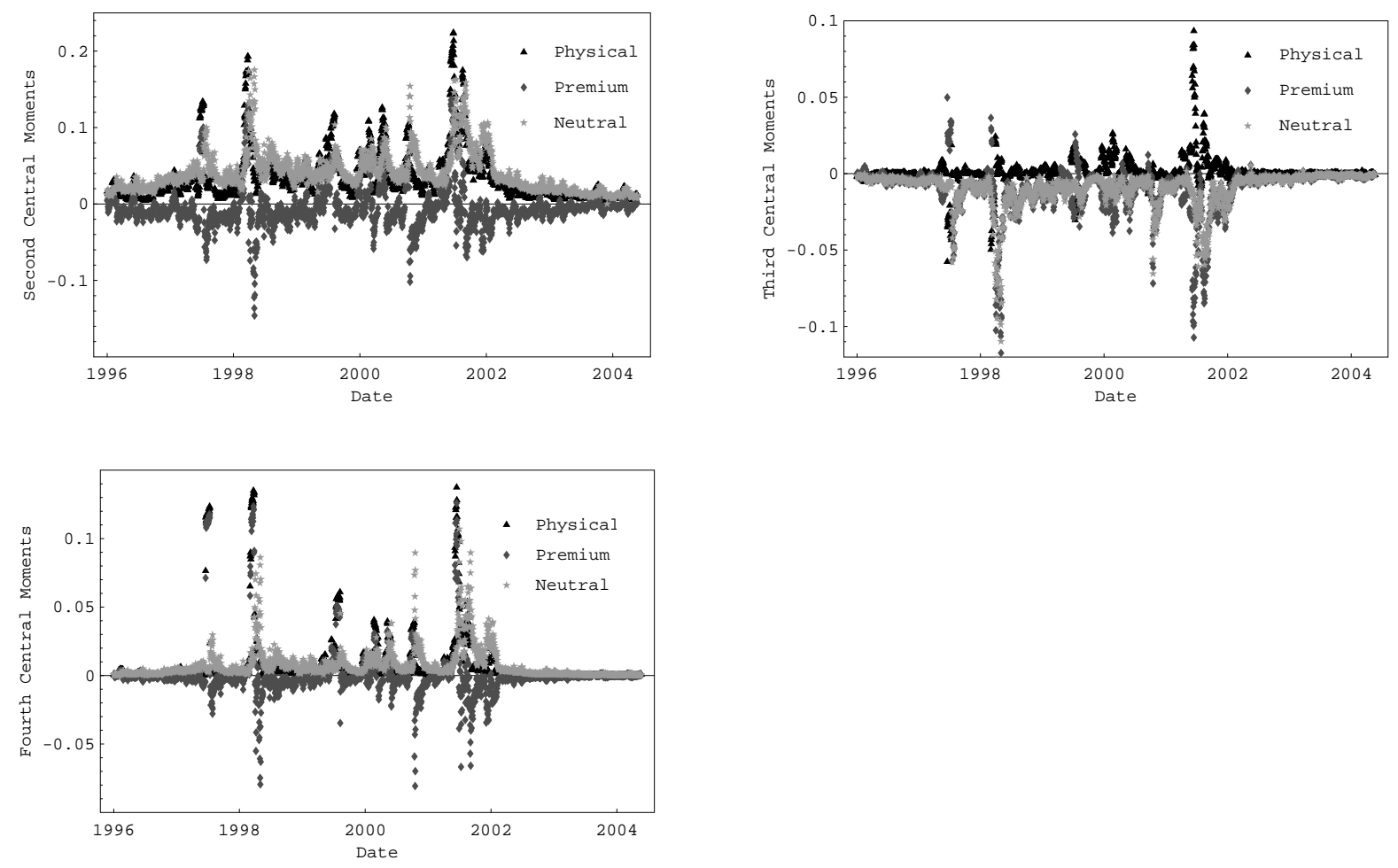
Figure 5: The variance, skewness and kurtosis risk premium for 90 days The figures plot respectively the daily changes of the second/variance risk premium, third/skewness risk premium, fourth/kurtosis risk premium(diamond points), the physical second/variance, third/skewness and fourth/kurtosis central moments (darkest triangle points) and the risk-neutral second/variance, third/skewness and fourth/kurtosis central moments (unfilled star points) from January 4, 1996 to December 30, 2005 for 90 days time to maturity. The variance/skewness/kurtosis risk premium is defined by the positive/negative/positive difference between the physical second/third/fourth central moments and the risk-neutral second/third/fourth central moments.
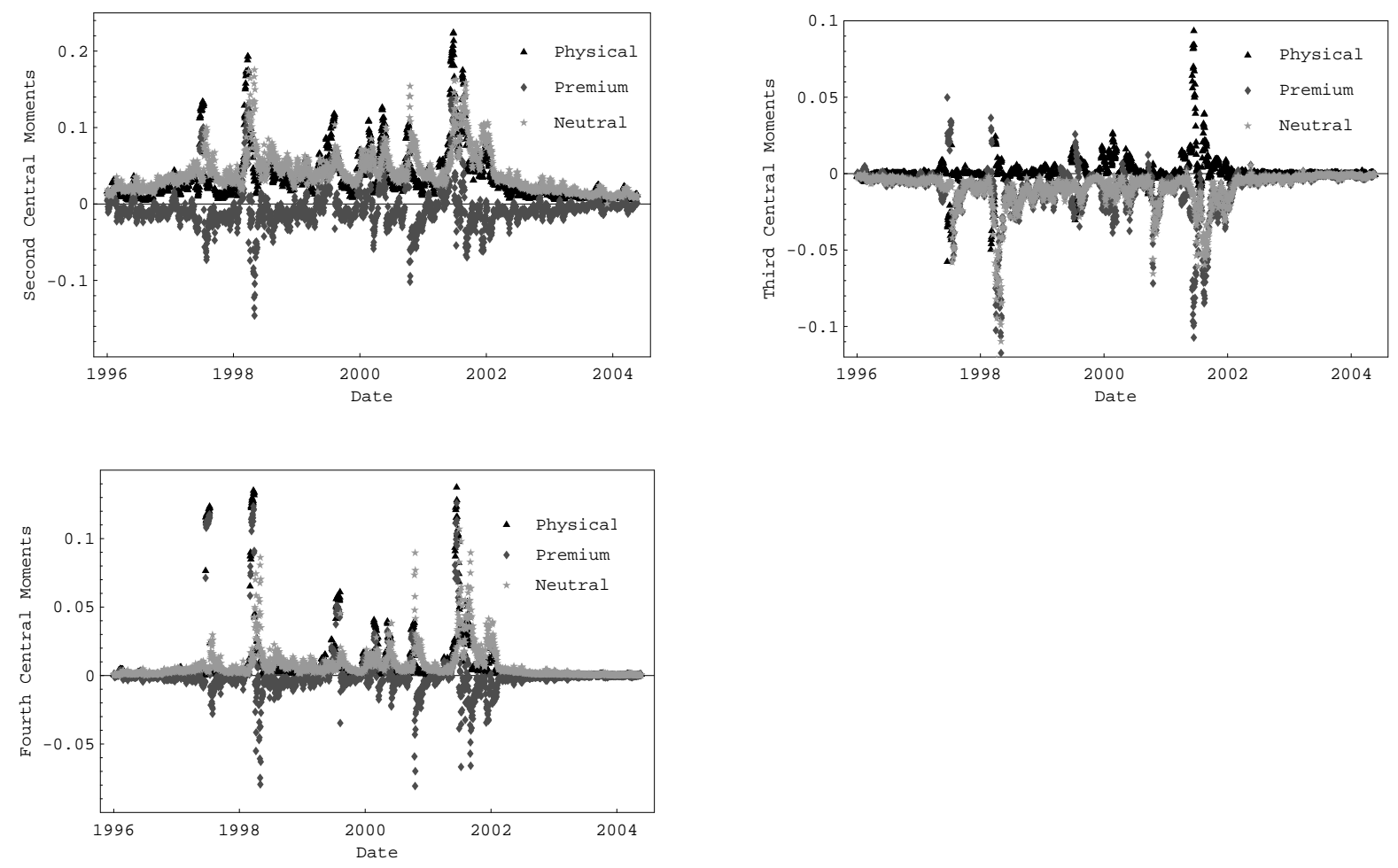